\title{
Factors associated with bullying at nurses' workplaces ${ }^{1}$
}

\author{
Kátia Biagio Fontes ${ }^{2}$ \\ Rosangela Getirana Santana ${ }^{3}$ \\ Sandra Marisa Pelloso ${ }^{4}$ \\ Maria Dalva de Barros Carvalho ${ }^{4}$
}

Objective: To identify nurses who are subject to workplace bullying and its associated factors. Method: Descriptive and exploratory study with a quantitative approach. The sample consisted of 199 nurses working in public and private sectors $(\mathrm{N}=388)$. For data collection, a graphic socio-professional questionnaire and the Leymann Inventory Psychological Terrorization were used, both in print or electronic format (May/September 2010). Results: According to the data collected, $11.56 \%$ of the participants had been subject to bullying. Multivariate analysis showed that having children, working at Public Healthcare Units, working at an institution for a period between one and three years, currently dealing with acts of bullying and to feel bullied are risk factors for bullying. Conclusion: This study permitted a better understanding of the factors associated with bullying; however, a research based on samples of Brazilian nurses is only the first step to evaluate other factors of influence related to the organizational context.

Descriptors: Nursing; Violence; Working Environment; Bullying; Interpersonal Relations; Occupational Health.

\footnotetext{
${ }_{1}^{1}$ Paper extracted from master's thesis: "Do invisível ao visível: assédio moral e o trabalho do enfermeiro", presented to Universidade Estadual de Maringá, Maringá, PR, Brazil.

2 Doctoral student, Universidade Estadual do Maringá, Maringá, PR, Brazil. Assistant Professor, Departamento de Enfermagem, Universidade Paranaense, Umuarama, PR, Brazil.

${ }^{3}$ PhD, Full Professor, Centro de Ciências Exatas, Universidade Estadual de Maringá, Maringá, PR, Brazil.

${ }^{4}$ PhD, Associate Professor, Centro de Ciências da Saúde, Universidade Estadual de Maringá, Maringá, PR, Brasil.
}

Corresponding Author:

Kátia Biagio Fontes

Universidade Paranaense. Departamento de Enfermagem

Praça Mascarenhas de Moraes, 4282

Bairro: Zona III

CEP: 87502-210, Umuarama, PR, Brasil

E-mail: katia.bf@gmail.com 


\section{Introduction}

Although there has been a concern about negative behavior among healthcare professionals in recent times, violence among these professionals is a reality in Brazil(1-2). A study undertaken in the country showed that nurses are dissatisfied with their job, due to a lack of good interpersonal relationships among healthcare professionals(3). Of the ethical professional nursing processes in course before the Regional Nursing Council of Santa Catarina, $17.7 \%$ were related to conflicting relationships among nursing professionals themselves and between nursing professionals and the healthcare team, most of them based on bullying $(42.85 \%)^{(4)}$. In the last few years, national studies have identified nurses who suffered this type of violence in the workplace ${ }^{(1,5-7)}$ and international studies show the vulnerability of these professionals in facing this situation ${ }^{(8-9)}$.

It is a hostile and unethical way of communicating, which is systematically administered by one person or by a few people against only one person who, as a consequence, is led to an extended situation of loneliness and exposure to frequent and persistent attacks ${ }^{(10)}$. One type of offensive and humiliating behavior is through vengeful, cruel and malicious attacks that disqualify, demoralize and are intended to demean an employee or group of employees ${ }^{(1)}$. In relation to its origin, it can be downwards (when a superior bullies a subordinate), upwards (when the superior is the one suffering bullying by one or several subordinates), horizontal (resulting from colleagues) or mixed ${ }^{(11)}$.

Not all disagreements in the workplace characterize bullying. What turns them into bullying is the frequency and repetition of the acts of violence. Leymann, the first academic to observe this kind of behavior in the workplace, established a definition in order to exclude temporary conflicts and characterize the potential victims of bullying. According to the author, for a person to be considered a potential victim, (s)he must have suffered frequent and persistent attacks (at least once a week) and for an extended period of time (for at least six months). This definition was based on physiologic concepts that establish a limit as from which this situation starts to cause psychological and psychosomatic damages(10). They are abusive behaviors that attempt against human dignity and can lead to illness or unexpected decisions relating to professional life, such as resignation or change of position/department(12).

Given the evidences found in the literature concerning bullying at nursing workplaces and the vulnerability of these professionals in the face of this situation, taking care of these professionals' workplace is of utmost importance. Therefore, understanding the factors that influence this type of violence becomes necessary, since nurses can act as agents of prevention and health promotion in their teams ${ }^{(13)}$. Therefore, the objective of this study was to identify the number of nurses who were victims of bullying and to determine the factors associated to workplace bullying.

\section{Method}

A descriptive and exploratory study with a quantitative approach was undertaken in Maringá, a city in the state of Paraná, Brazil, with approval from the Permanent Research Ethics Committee at Universidade Estadual de Maringa (Registration number 003/2010). There were 199 participants in this study, from a population of 388 nurses (reliability rate of $0.95 \%$, margin of error $0.05 \%$ ) who worked at public and private institutions. Those who were part of this population were nurses working at public and private hospitals, Public Healthcare Units, Council Health Department, Regional Healthcare Unit, Blood Banks, Intercity Healthcare Partnership, Prison, Fire Department, Private Healthcare Clinics, Asylum type institutions, Health Insurances, Urgency and Emergency Services. Nurses working at eight public healthcare units were not part of this research, due to non-authorization by the directors.

The exclusion criteria were nurses with less than one year of professional experience, those who participated in the pilot test or who were on holiday, sick leave, award leave and maternity leave at the time of data collection.

A graphic socio-professional questionnaire was especially developed for this research and consisted of the following questions: gender, race, age group, level of education, marital status, children, length of professional practice, number of jobs, area/sector of professional activity, employment type, time working in the institution, shift and remuneration. In order to identify the employees who had been bullied in the last twelve months, the Leymann Inventory Psychological Terrorization (LIPT-45) ${ }^{(14)}$ was used, which was translated and adapted for use in Brazil. This tool consists of 45 questions and is divided into five dimensions that represent the different behaviors of bullying in the workplace: 1 ) bullying activities aimed at reducing the chances of the victim adequately communicating with other people, including the bullies themselves; 2) bullying 
activities to prevent the victim from maintaining social contacts; 3) bullying activities aimed at discrediting the victims to maintain their personal and professional reputation; 4) bullying activities aimed at belittling the work performed by the victims and their employability, through professional discredit; 5) bullying activities that affect the physical and psychological health of the victim. Three questions were added at the end of the questionnaire, which addressed issues like the nurses' currently facing some kind of bullying mentioned by the LIPT-45, whether they witnessed work colleagues being victims of such behaviors and the perception of nurses in relation to whether or not they were victims of bullying. All nurses who reported to have suffered at least one of the behaviors referred to in the LIPT-45, at a frequency of at least once a week and for a period of at least six months, were considered to have been victims of bullying.

Both the research tools and the Informed Consent Form (TCLE) were converted to an electronic format and saved into the web page of the Post-Graduate Nursing Program, which researchers are linked to, given that the main form of data collection was via web.

Before applying the electronic questionnaire to the sample, a pilot test was performed with 27 nurses, who were part of a group of 44 post-graduate students in the Post-Graduate Nursing Program, in order to detect any deficiencies in the graphic socio-professional tools and in the research layout.

After receiving authorization from the Research Ethics Committee, the nurses were contacted by phone at their respective institutions and invited to participate in the research. Those who agreed were asked to give their emails and, those who did not have one, their post addresses. To the nurses, a "Research Presentation Email" was sent, informing its purpose, the registration of the emails of the people selected at the place of research and clarifications about how to proceed. After this step, a simple random drawing was performed, using the Program Excel. The selected people had their emails registered at the place of research, which automatically generated personalized passwords (of access and secondary, useful in case a person decided to withdraw from the study) and directed them to the registered emails, together with the link of the research. They were also informed that, if they decided not to participate in the research, they just needed to send the secondary password to the researcher by email and she would promptly exclude their emails from the system. Once the emails were registered, a new telephone contact with the people was carried out, informing about the procedure. Also, a "Support Manual" was sent by email with information in case of difficulty in participating. An email reminding about the participation was automatically sent by the system once a week.

To the nurses who did not have an email, the TCLE was sent by post or hand delivered, together with the research presentation letter and the printed questionnaire. Together with the questionnaire sent by post, a pre-paid and self-addressed envelope was enclosed.

At the end of a twenty-day period, the exclusion of the place of research from the emails of the selected nurses who did not respond was undertaken. A new random procedure was then carried out to replace the excluded nurses, and so forth, until obtaining the sample. Data collection took place between May and September 2010. Once a month, a report with the preliminary results of the research was emailed to the study participants.

The data were organized in tables with absolute frequencies and percentages. For the sake of univariate comparisons, the Pearson's Chi-square and Fisher's tests were used, considering bullying as the response variable. To identify the factors associated with bullying, a logistic regression model was developed through multivariate analysis. In this step, each of the categorized independent variables was analyzed with the response variable. In order to expand the analysis model, those that reached a value of $p<0.20$ in the univariate analysis were selected for the logistic model(16). In the final model, the variables that reached significance levels of $p<0.05$ were considered significant. The statistical programs used for the univariate and multivariate analysis were Statistica 8.0 and the Statistical Analysis System (SAS 9.1). In all of the analyses, the significance level was set at $p \leq 0.05$, with a reliability rate of $95 \%$ for all tests.

\section{Results}

Of those who had their emails selected and registered at the place of research, five requested exclusion from the system. Once the questionnaires were given to the participants, none of them regretted participating in the study.

Regarding the type of participation, 175 (87.94\%) happened through a web-based electronic questionnaire and $24(12.06 \%)$ through a printed questionnaire.

The participants in the study were predominantly female (88.94\%), with an average age of 36.6 (standard 
deviation \pm 8.11$)$, Caucasian (89.45\%), married $(62.81 \%)$, specialists $(68.84 \%)$, with professional activity between 4 and 9 years (30.15\%), on a permanent employment (57.29\%) and remuneration over $\mathrm{R} \$ 2,500(64.32 \%)$, that is, around almost five times the minimum wage.

According to the Leymann criteria, 23 (11.56\%) of the studied participants had been bullied in the last 12 months, that is, they were victims of at least one bullying behavior per week over a period of at least six months.
It could be noted that the group reporting to have been bullied was mostly female (52.2\%). As for the number of bullies, most of the victims were bullied by two to four people (39.1\%), followed by those who were bullied by one person (34.8\%) and those by more than four people $(26.1 \%)$. Unfortunately, it was not possible to identify the origin of bullying (whether downwards, upwards, horizontal or mixed), due to a functional error in the web system during the analysis stage.

Table 1 - Univariate analysis of victims of bullying, characterized according to the Leymann criteria, and factors of interest. Maringa, PR, Brazil, 2010

\begin{tabular}{|c|c|c|c|}
\hline \multirow{2}{*}{ Variable } & \multicolumn{2}{|c|}{ Victim of bullying } & \multirow{2}{*}{ p-value } \\
\hline & No & Yes & \\
\hline \multicolumn{4}{|l|}{ Children } \\
\hline Yes & 108 & 19 & 0.0462 \\
\hline No & 68 & 4 & \\
\hline \multicolumn{4}{|l|}{ More than one job } \\
\hline Yes & 51 & 1 & 0.0115 \\
\hline No & 125 & 22 & \\
\hline \multicolumn{4}{|l|}{ Area/professional industry sector } \\
\hline Public hospital & 33 & 2 & \\
\hline Private hospital & 43 & 6 & 0.0019 \\
\hline Public Healthcare Units & 23 & 10 & \\
\hline Other healthcare services & 77 & 5 & \\
\hline \multicolumn{4}{|l|}{ Length of employment in the institution } \\
\hline 1 to 3 years & 57 & 11 & \\
\hline 4 to 8 years & 41 & 6 & $0.1675^{*}$ \\
\hline 9 to 15 years & 50 & 2 & \\
\hline$\geq 16$ years & 28 & 4 & \\
\hline \multicolumn{4}{|c|}{ Witnessed colleagues being victims of bullying } \\
\hline Yes & 108 & 21 & 0.0047 \\
\hline No & 68 & 2 & \\
\hline \multicolumn{4}{|c|}{ Is currently dealing with bullying behaviors } \\
\hline Yes & 46 & 19 & $<0.0001$ \\
\hline No & 130 & 4 & \\
\hline \multicolumn{4}{|l|}{ Feels bullied in the workplace } \\
\hline Yes & 40 & 19 & $<0.0001$ \\
\hline No & 136 & 4 & \\
\hline
\end{tabular}

*Fisher's Exact Test was used

According to the univariate analysis, bullying was associated with the following variables: children, more than one job, area, professional industry sector, whether they witnessed colleagues being victims of bullying, are currently dealing with bullying behaviors in the workplace, whether they feel bullied in the workplace
(Table 1). The variables gender, race, age group, educational level, marital status, length of professional activity, employment status, length of employment in the institution and remuneration were not associated with bullying. 
Table 2 - Multivariate analysis of risk factors for bullying among nurses. Maringa, PR, Brazil, 2010

\begin{tabular}{lccc}
\hline \multicolumn{1}{c}{ Variables } & OR adjusted & RL (95\%) & p \\
\hline Having children & 15.02 & $2.88-78.30$ & $<0.01$ \\
Working at Public Healthcare Unit & 10.61 & $1.19-94.97$ & 0.03 \\
Working at the institution for a period between 1 and 3 years & 13.96 & $1.22-160.29$ & 0.03 \\
Being currently dealing with bullying in the workplace & 8.84 & $162-48.13$ & 0.01 \\
Feeling bullied & 7.44 & $1.52-36.47$ & 0.01 \\
\hline
\end{tabular}

After the entry of the variables that had a $p$-value $<20$ (Table 1 ), the results of the final logistic regression model ( $p$ values, adjusted odds ratio and reliability rate), with significance level of $5 \%$, are displayed in Table 2. The profile of nurses with potential risks of being bullied in the workplace is: having children, working at Public Healthcare Unit, working at the institution for a period between one and three years, being currently dealing with bullying in the workplace and feeling bullied.

\section{Discussion}

According to the Leymann criteria, $11.56 \%$ of the studied participants are potential victims of bullying. A similar result, based on the same criteria, was found among nurses working in the public sector in Portugal $(13 \%)^{(8)}$.

According to the logistic model, having children contributed to the occurrence of bullying ( $O R=15.02)$. Like in other studies, most participants in the present one were female, married and had children. At current times, women have greatly contributed to the family income, and at times even play an important role as the sole family provider.

Fear represses any act being taken in defense of dignity. The fight to maintain their jobs as a way of survival has become, for those who still work, maximum priority for being a source of suffering(17). It is possible that these female nurses, given their family responsibilities, insist on remaining in their jobs, even being victims of bullying, due to the fact that they are their only source of income. Consequently, they may take a submissive stance. In contrast, their superiors may use this condition to intimidate their victims by threatening to sack them as they wish.

The chances of nurses who work in Public Healthcare Units being victims of bullying were 10.61 times higher when compared to other areas/sectors $(O R=10.61)$. The professionals who were part of the category "Public Healthcare Units" in the present study performed their duties as nurses at Public Healthcare Units, Policlinics and Family Healthcare Program. What can be seen is that negative behaviors in the workplace have often not been verified, or even worse, have been accepted as part of the organizational system(18). A qualitative study involving nurses working in the public sector who had been bullied revealed that the corrupt bullying behaviors took place behind closed doors, not being formally recognized and verified, thus becoming habitual and institutionalized(19). In the public sector, bullying can last for years because the victims cannot be sacked and the priority is often the wish to maintain the stability of one's job, to the detriment of maintaining their own dignity. For this reason, the methods used in this sector are more harmful and can have a catastrophic impact on the victim's health. Another aggravating factor in the public sector is the difficult access to higher ranking employees when people wish to be heard in relation to their interpersonal problems with their superior ${ }^{(11)}$. Therefore, such work environments are a risk for the development and maintenance of bullying.

Another point to be considered is that, in the public sector, bullying is not related to productivity as it is in the private sector, but is associated with power disputes $^{(11)}$. A study carried out at a public university hospital showed that $73.3 \%$ of the doctors interviewed stated that there is a dispute of power between doctors and nurses at some stage in their interprofessional relationship, and that $90.9 \%$ of them feel that this situation can cause ethical problems between the categories $^{(20)}$. However, when analyzed from the point of view of the nurses working at the mentioned institution, poor communication was pointed out as creating conflicts between these professionals(21).

A previous study showed that, in the workplace of the studied nurses, psychological violence mainly originated in women. The authors suggest that this result can be related to the competition among them, caused by the fact that they are continuously seeking public recognition at work ${ }^{(5)}$. In this study, most victims also pointed out female professionals as sources of bullying behaviors. However, this finding should not 
be interpreted as related to gender, but due to the workplace structure of the healthcare sector itself, which is predominantly characterized by women.

In this study, working for a period between one and three years $(O R=13.96)$ appears as the factor most strongly associated with bullying. A similar result was found in a study carried out in China and involving nurses and nursing teams of a psychiatric hospital, which showed that a period under four years working in the institution was associated with bullying(22). It can be concluded that nurses working longer in the institution have more security, authority and, consequently, more capacity to deal with bullying.

Currently dealing with bullying behaviors favored the occurrence of bullying $(\mathrm{OR}=8.84)$. A Chilean study showed that the development and maintenance of bullying in the nursing context are influenced by coping strategies used by the victims, formative aspects of the profession, historical and cultural contexts and organizational features ${ }^{(23)}$. Whilst considering that most of the studied nurses who were identified as bullying victims in the last 12 months were still dealing with bullying at the time of the study, it can be concluded that they were still working at the same institution, had not developed effective strategies to deal with bullying or even found support in the workplace. Effective measures to deal with bullying in the workplace are important, but not sufficient if there is not an organizational policy to prevent this type of violence.

Nurses who had the perception they were being bullied in the workplace had 7.44 times more chances of being bullied than those who did not feel they were being bullied $(O R=7.44)$. Due to it being a disguised type of violence, most times, only the victim realizes the bad intentions and the bullies can easily be seen as defending the interests of the institution as part of their jobs $^{(11)}$. Therefore, taking into consideration the victim's complaints becomes a valuable indicator when assessing the occurrence of bullying in the workplace.

A situation only has a meaning through people's subjectivity ${ }^{(11)}$, so being aware of the problem they are experiencing becomes critically important in order to break the silence and seek support to deal with this type of violence.

\section{Conclusion}

One of the limitations of this study was the lack of identification of the origins of the bullying (if horizontal, downwards or upwards), due to a functional error in the web system during the analysis stage. This limitation was, however, overcome by the results that enable the understanding about the dimension of bullying among nurses.

Unlike other international studies that identified nurses who felt they were being victims of bullying, one of the main objectives of this study was to identify nurses who had been victims, based on the Leymann criteria. The results of this study pointed out that $11.56 \%$ of the nurses were identified as victims of bullying.

The present study permitted to identify the determining factors of bullying: having children, working at Public Healthcare Unit, working at the institution for a period between 1 and 3 years, being currently dealing with bullying in the workplace and feeling bullied. It is expected that this study can support future researches, as well as managers, human resources professionals and nurses, in identifying vulnerable populations.

This way, it will be possible to protect this population through the adoption of strategic measures of prevention and containment of this highly demeaning type of violence in the workplace. Effective measures dealing with bullying in the workplace are important, but will not be sufficient if there is not an organizational policy to prevent it.

Given the lack of studies about the subject in Brazil, it is believed that this research will serve as a support to understand the determining factors of bullying in the organizational context of nursing in the country.

\section{References}

1. Xavier ACH, Barcelos CRV, Lopes JP, Chamarelli PG, Ribeiro SS, Lacerda LS, et al. Workplace moral harassment in Rio de Janeiro health sector: some characteristics. Rev Bras Saúde Ocup. 2008;33(117):15-22.

2. Molinos BG, Coelho EBS, Pires ROM, Lindner SR. Violence against primary health care professionals: a study in the interior of the brazilian amazon. Cogitare Enferm. 2012;17(2):239-47.

3. Jeong DJY, Kurcgant P. Factors of work dissatisfaction according to the perception of nurses of a university hospital. Rev. gauch. enferm. 2010;31(4):655-61.

4. Schneider DG, Ramos FRS. Nursing ethical processes in the State of Santa Catarina: characterization of factual elements. Rev. Latino-Am. Enfermagem. jul.ago. 2012;20(4):744-52.

5. Barbosa R, Labronici LM, Sarquis LMM, Mantovani MF. Psychological violence in nurses' professional practice. Rev. Esc. Enferm. USP. 2011;45(1):26-32. 
6. Fontes KB, Carvalho MDB. Variables involved in the perception of psychological harassment in the nursing work environment. Rev. Latino-Am. Enfermagem. jul.ago. $2012 ; 20(4): 761-8$.

7. Vasconcellos IRR, Abreu AMM, Maia EL. Violência ocupacional sofrida pelos profissionais de enfermagem do serviço de pronto atendimento hospitalar. Rev. gauch. enferm. 2012;33(2):167-75.

8. Sá L, Fleming MF. Bullying, burnout, and mental health amongst portugueses nurses. Issues Ment Health Nurs. 2008;29(4):411-26.

9. Efe SY, Ayaz S. Mobbing against nurses in the workplace in Turkey. Int. nurs. rev. 2010;57(1):328-34. 10. Leymann $\mathrm{H}$. The content and development of mobbing at work. Eur. J Work Organiz Psychol. 1996;5(2):165-84. 11. Hirigoyen MF. Mal-estar no trabalho: redefinindo o assédio moral. 4. ed. Rio de Janeiro: Bertrand Brasil; 2009. $350 \mathrm{p}$.

12. Battistelli BM, Amazarray MR, Koller SH. Mobbing at work according to operators of the law. Psicol. soc. 2011;23(1):35-45.

13. Leitão IMTA, Fernandes AL, Ramos IC. Occupational health: analyzing the risks related to a nursing team in an Intensive Care Unit. Cienc. cuid. saude. $2008 ; 7(4): 476-84$.

14. Leymann $H$, Tallgren $U$. Undersokning av frekvensen vuxenmobbning inom SSAB (Investigation into the frequency of adult mobbing in SSAB a Swedish steel company using the LIPT questionnaire). Arbete, Miinniska. 1989;1(1):111-5.

15. Barreto M. Assédio moral: a violência sutil: análise epidemiológica e psicossocial no trabalho no Brasil. [Tese de Doutorado]. São Paulo (SP): Pontifícia Universidade Católica; 2005.

16. Hosmer DW, Lemeshow S. Applied logistic regression. 2. ed. New Yor: John Wiley \& Sons; 2000. 374 p.

17. Barreto, M. Violência, saúde e trabalho: uma jornada de humilhações. 2. ed. São Paulo: EDUC; 2006. 233 p.

18. Longo J. Combating Disruptive Behaviors: Strategies to Promote a Healthy Work Environment. Online J. Issues Nurs. [internet]. 2010 [acesso em: 07 nov 2012];15:11. Disponível em: http://www.nursingworld.org/ MainMenuCategories/ANAMarketplace/ANAPeriodicals/ OJIN/TableofContents/Vol152010/No1Jan2010/ Combating-Disruptive-Behaviors.html

19. Hutchinson M, Vickers M, Wilkes L, Jackson D. "The worse you behave, the more you seem, to be rewarded": bullying in nursing as organizational corruption. Employ Respons Rights J. 2009;21(3):213-29.
20. Oliveira AM, Lemes AM, Machado CR, Silva FL, Miranda FS. Professional relationship between nurses and doctors at the hospital of medical school: the view of doctors. Rev. bras. saude mater. infant. 2010; 1 Suppl. 2: S433-S39.

21. Oliveira AM, Lemes AM, Ávila BT, Machado $C R$, Ordones E, Miranda FS, et al. Professional relationship between nurses and doctors at the clinical hospital of federal university of goiás: the view of nurses. Rev. latinoam. bioet. 2010;10(2):58-67.

22. Chen W, Sun Y, Lan T, Chiu H. Incidence and Risk Factors of Workplace Violence on Nursing Staffs Caring for Chronic Psychiatric Patients in Taiwan. Int. J. Environ. Res. Public Health. 2009;6(1):2812-21.

23. Castellón AMD. Occupational Violence in Nursing: Explanations and Coping Strategies. Rev. Latino-Am. Enfermagem. 2011;19(1):156-63. 